\section{Delta and Serrate are redundant Notch ligands required for asymmetric cell divisions within the D rosophila sensory organ lineage}

\author{
Chaoyang Zeng, Susan Younger-Shepherd, \\ Lily Y. Jan, and Yuh Nung Jan ${ }^{1}$ \\ Howard Hughes Medical Institute and Departments of \\ Physiology and Biochemistry, University of California, San \\ Francisco, California 94143 USA
}

\begin{abstract}
Asymmetric divisions allow a precursor to produce four distinct cells of a Drosophila sensory organ lineage (SOL). Whereas this process requires cell-cell communication via Notch $(\mathrm{N})$ receptor, mitotic recombination that removes the $\mathbf{N}$ ligand Delta (DI) or Serrate (Ser) in the SOL had mild or no effect. Removal of both DI and Ser, however, led to cell fate transformations similar to the $\mathrm{N}$ phenotype. Cell fatetransformation occurred even when a single SOL cell lost both DI and Ser. Thus, D I and Ser are redundant in mediating signaling between daughter cells to specify their distinct cell fates.
\end{abstract}

Received January 12, 1998; revised version accepted February 26, 1998.

$\mathrm{N}$ otch ( $\mathrm{N}$ )-mediated signaling between cells is required for the formation of the adult external sensory organs (bristles) in two different developmental processes (Hartenstein and Posakony 1989, 1990; de Celis et al. 1991; Heitzler and Simpson 1991; Parks and Muskavitch 1993; Posakony 1994; Jan and Jan 1995; Parks et al . 1997; Wang et al. 1997). First, N mediates lateral inhibition, a process by which a single cell is sel ected from an equivalence group of competent cells to become the sensory organ precursor (SOP) (Heitzler and Simpson 1991, 1993). Second, $\mathrm{N}$ functions in the correct execution of three asymmetric cell divisions in a fixed sensory organ lineage (SOL), leading to the generation of four distinct cells that form a sensory organ (bristle). The SOP first divides into two different secondary precursor cells, IIA and IIB, which gives rise to one shaft-producing cell (trichogen) and one socket-producing cell (tormogen), and one neuron and one sheath cell (thecogen), respectively (see Fig. 4C, below). These four lineage-related cells constitute the SOL (Bodmer et al. 1989; Hartenstein and Posakony 1989; Posakony 1994; Rhyu et al. 1994).

Although $\mathrm{N}$ signaling is known to be required for

[Key Words: Notch; Delta; Serrate; sensory organs; asymmetric cell divisions; Drosophila]

${ }^{1}$ Corresponding author.

E-MAIL ynjan@itsa.ucsf.edu; FAX (415) 476-5774. specifying the SOL, two questions have not been adequately addressed: First, what is the identity of the relevant N ligand? Delta (DI) and Serrate (Ser) are two known ligands for $\mathrm{N}$, and $\mathrm{DI}$ has been implicated as the $\mathrm{N}$ ligand that specifies cell fates of the SOL (Fehon et al. 1990; Fleming et al. 1990; Thomas et al. 1991; Parks and Muskavitch 1993; Parks et al. 1997). However, it is not known whether DI is the only ligand involved. Second, which cells partici pate in the $\mathrm{N}$-mediated signaling that enables the daughter cells to acquire distinct cell fates in these asymmetric divisions? A priori, the $\mathrm{N}$ ligand(s) could be provided by the neighboring epidermal cells (Fig. 1A), by the sibling cells within the SOL (Fig. 1B), or by both groups of cells (Fig. 1C). In the Drosophila CN S, the MP2 cell divides asymmetrically to produce a pai $r$ of distinct neurons, and both $\mathrm{N}$ and numb are required for this asymmetry. The $\mathrm{N}$ ligands required for this process are thought to be provided by the neighboring epidermal cells and not by the cells within the M P2 lineage (Spana and Doe 1996). In the SOL, there have been no experimental tests to distinguish among these scenarios.

To examine the source and identities of the $\mathrm{N}$ ligands during each step of the SOL, we induced mitotic recombination after SOP formation to specifically remove gene functions from marked mutant clones. Within the $\mathrm{N}$ mutant clone, both daughter cells adopted the same fate. Removal of DI rarely gave rise to cell fate transformation in the mutant clones, and removal of Ser failed to produce detectable cell fate transformation. In contrast, removal of both DI and Ser led to cell fate transformations reminiscent of the $\mathrm{N}$ phenotype. Thus Ser functions in the specification of daughter cell fates during the asymmetric divisions of the SOL, which is normally masked by the redundant function of DI. Moreover, removal of both $\mathrm{DI}$ and Ser function from a single cell within the SOL resulted in the transformation of the cell fate, indicating that daughter cell fates are determined mainly by signaling between the two siblings.

\section{Results and Discussion}

The phenotype of $\mathrm{N}$ clones is different from the phenotype of DI clones

We used the yeast site-specific recombinase FLP to induce mitotic recombination (Golic and Lindquist 1989; Xu and Rubin 1993) and thereby produce clones of homozygous $\mathrm{N}$ mutant cells in otherwise heterozygous flies. $\mathrm{N}$ mutant clones generated on the central region of the adult scutum were devoid of any external bristle structures such as shafts and sockets (Fig. 2A), similar to the $\mathrm{N}^{\text {ts }}$ mutant phenotype at restrictive temperature (Hartenstein and Posakony 1990; Wang et al. 1997). Whereas loss of $\mathrm{N}$ function during the process of lateral inhibition produces supernumerary SOPs (Heitzler and Simpson 1991, 1993), this bal ding phenotype is probably due to the requirement of $\mathrm{N}$ in asymmetric divisions. Without $\mathrm{N}$ activity the supernumerary SOPs di vide symmetrically, giving rise to two IIB cells and, consequently, 
A

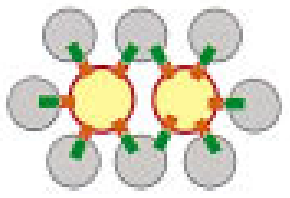

B

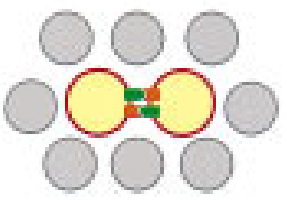

C

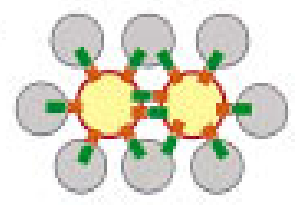

Figure 1. The three possible ways of supplying $N$ ligands during the asymmetric cell divisions within the SOL (after Guo et al. 1996). (A) The N ligands could be supplied by non-SOL cells; (B) the sibling cells might be signaling to each other; (C) a combination of the two scenarios is also possible. (Gray circles) Epidermal cells; (yellow circles) SOL cells; (green $\mathbf{D}) \mathrm{N}$ ligands; (brown $\mathbf{E}) \mathrm{N}$ receptors.

no external sensory structures (Hartenstein and Posakony 1990; Heitzler and Simpson 1991, 1993; Wanget al . 1997).

$\mathrm{DI}$ is a ligand for $\mathrm{N}$ during bristle development (Fehon et al. 1990; Parks and M uskavitch 1993; Artavanis-Tsakonas et al. 1995; Parks et al. 1997). However, in contrast to $\mathrm{N}$ mutant clones, similarly induced DI clones typically gave rise to a tuft of densely packed bristles in the interior of the clone (Fig. 2B). These tufts of bristles are likely due to a failure of Iateral inhibition, resulting in overproduction of SOPs (Heitzler and Simpson 1991, 1993). The presence of the external bristle structures in these DI mutant clones indicates that, unlike $\mathrm{N}$ clones, most of the supernumerary SOPs in the DI mutant clones produce IIA cells that divide to form shaft and socket cells.

To test for Ser invol vement in bristle devel opment, we generated mitotic clones of Ser, and clones of DI Ser double mutations. Clones homozygous for three Ser null alleles gave rise to normal external bristle structures (Fig. 2C). In contrast, cl ones with loss of both DI and Ser function produced epidermal cells but not external bristle structures (Fig. 2D). This balding phenotype is clearly different from the phenotypes of the DI or Ser mutant clones but is indistinguishable from that of $\mathrm{N}$ mutant clones, suggesting that Ser and DI have overlapping functions in the $\mathrm{N}$ signaling pathway.

Ser and DI are redundant signals to $\mathrm{N}$ for the specification of different daughter cell fates in the SOL

To examine the role of $\mathrm{DI}$ and Ser in the SOL asymmetric divisions, we used SOL-specific Gal 4 enhancer trap lines, Gal4 ${ }^{109-68}$ (Frise et al. 1996) or sca-Gal4 (N akao and Campos-Ortega 1996), to drive FLP recombinase expression from a UAS-FLP transgene, which allows mitotic recombination mainly within the $\mathrm{SOL}$, after the SOP cell is singled out via lateral inhibition. Because a typical SOL undergoes only two rounds of cell divisions (Bodmer et al. 1989; Hartenstein and Posakony 1989; Posakony 1994), each mutant "clone" consists of only one or two homozygous mutant cells depending on when the recombination takes place.

The loss of Ser function in such a mutant clone produced normal external bristle structures (Fig. 3A); of the 23 marked macrochaetae clones, no double shafts (i.e., macrochaetae with two shafts and no associ ated sockets)

were seen. Similarly generated DI mutant clones were largely normal (Fig. 3B); only $~ 5 \%$ of the marked mutant macrochaetae exhibited double shafts. In contrast, double mutant clones with loss of both DI and Ser function within the SOL frequently exhibited double shafts (Fig. 3C); $\sim 44 \%$ of the marked macrochaetae clones had double shafts. This is much more severe than the phenotype of DI or Ser clones but similar to the phenotype of $\mathrm{N}$ clones generated in similar fashion (Fig. 4B), where $39 \%$ of the single $\mathrm{N}$ macrochaetae clones had double shafts.

Unlike processes such as the wing blade formation where Ser serves a distinct function as a compartmentspecific signal (Diaz-Benjumea and Cohen 1995; Doherty et al. 1996; Jonsson and Knust 1996; de Celis et al. 1997; Michelli et al. 1997), our results indicate that the function of Ser in the SOL is similar to that of DI. Ser's function in bristle development has not been identified previously (Fleming et al. 1990; Thomas et al. 1991; Speicher et al. 1994), because it is normally masked by the

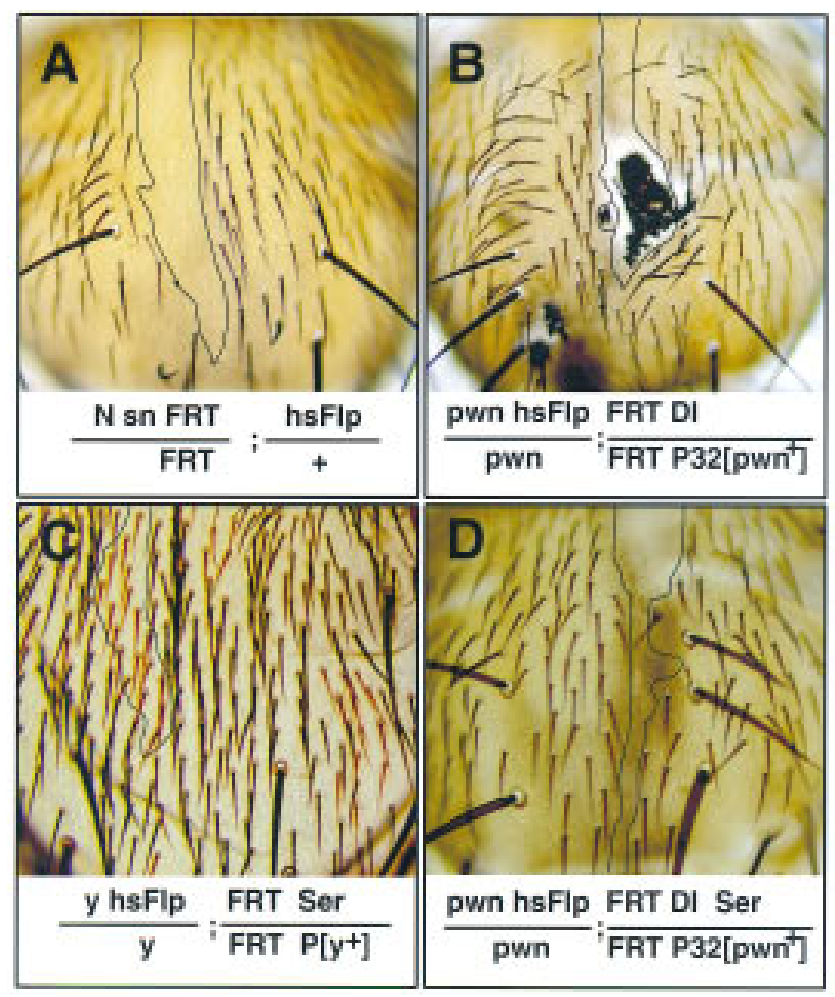

Figure 2. The contribution of Ser to cell fate specification of the SOL is uncovered when DI is al so removed. Doubly mutant clones of $\mathrm{DI}$ and Ser (D) display a phenotype that is similar to that of $N(A)$ but different from that of DI (B) or Ser clones (C). For each genotype, a large representative clone (boundaries indicated by black lines) found on similar regions of the adult scutum is shown. (A) N clones; (B) DI clones; (C) Ser mutant; (D) DI Ser doubly mutant clones. 

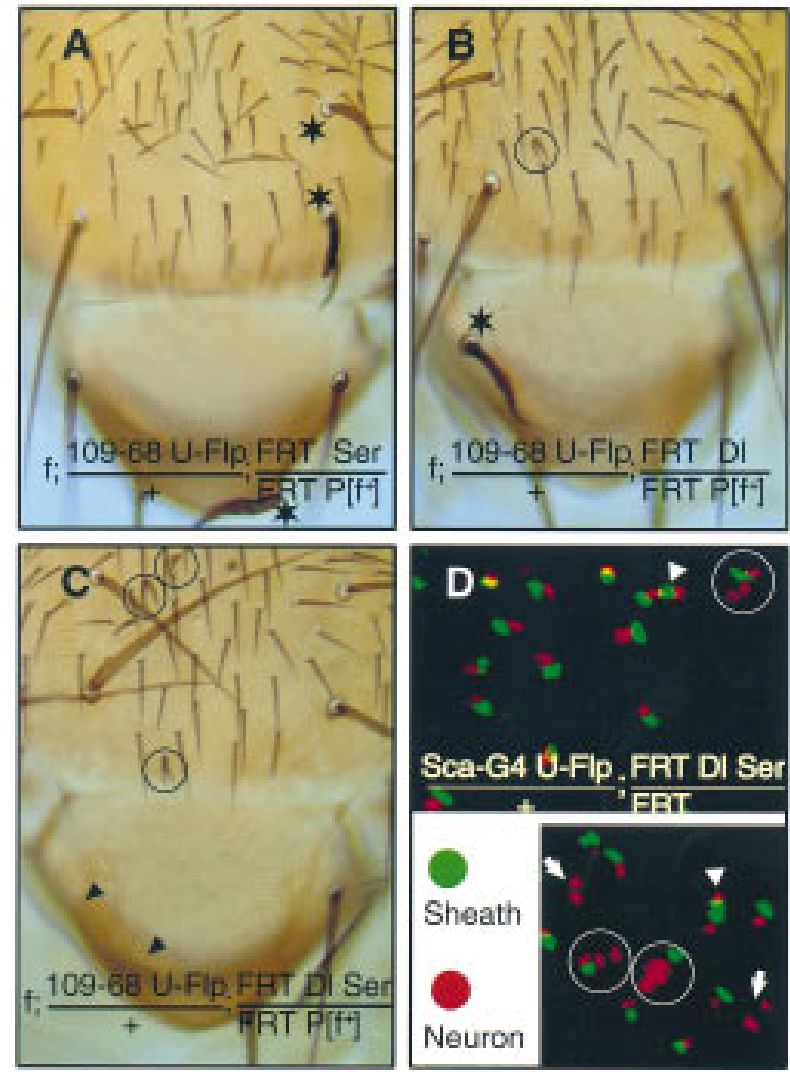

Figure 3. Both $\mathrm{DI}$ and Ser can signal to $\mathrm{N}$ receptor during the asymmetric cell divisions within SOL. (A) Ser mutant macrochaetae, marked by $f$, have a normal complement of external structures (stars). (B) DI mutant bristles, such as the macrochaetae (star), do not display cell fate transformation phenotypes, whereas some bristles have double shafts but no sockets (circled). (C) DI Ser double mutant clones. (A rrowheads) Loss of external sensory structures, or balding; (circles) double-shaft bristles with no sockets. (D) Internal cell fate transformations in DI Ser mutant clones as indicated by immunofluorescent staining of pupal nota 24-30 hr APF with neuron-specific anti-Elav (red) and sheath cell-specific anti-Prospero (green) antibodies. Closely associated clusters of 3 neurons and 1 sheath (encircled), 2 neurons and 2 sheath (arrowheads), and 2 neurons with no sheath (arrows) are indicated; the remaining clusters each have 1 neuron and 1 sheath.

redundant function of DI. Only when DI function is reduced or eliminated can we detect the contribution of Ser to SOL cell fate specification. Similarly, al though DI is essential for lateral inhibition and loss of DI function produces a strong neurogenic phenotype, the function of DI during the subsequent asymmetric cell divisions can be substituted almost entirely by Ser. These observations reinforce the notion that Ser and DI are redundant signals to $\mathrm{N}$ for the specification of daughter cell fates of asymmetric cell divisions in the SOL.

The source of $\mathrm{N}$ ligands resides within the $\mathrm{SO} \mathrm{L}$ during the asymmetric cell divisions

A current model of sensory organ development postu- lates that the $\mathrm{N}$ ligands are provided by daughter cells within the SOL to influence their sibling cell fates (Posakony 1994; Jan and Jan 1995; Frise et al. 1996). However, the source of the $\mathrm{N}$ ligands has not been identified experimentally. Either the daughter cells of the asymmetric divisions or their neighboring epidermal cells could be providing the $\mathrm{DI}$ and/ or Ser function for the $\mathrm{N}$ receptor (Fig. 1). To identify the cells that provide the DI and Ser for the specification of the daughter cell fates, we analyzed UAS-FLP-induced clones with two distinct bristle morphol ogy markers. As a result of FRT-mediated recombination, the daughter cell that was homozygous for both DI and Ser mutations was homozygous for the bristle color mutation yell ow (y), whereas its sibling cell, wild-type for DI and Ser, was homozygous for the bristle mutation Stubble (Sb). The cells that did not undergo mitotic recombination were heterozygous for $\mathrm{DI}$, Ser, Sb, and y.

Our experiments produced clones with abnormal bristles composed of double shafts without associated sockets. Interestingly, some of these double shafts consisted of one yellow shaft and one stubble shaft (Fig. 4A, purple arrow). The double shafts most likely arose from a recombination event during the division of onelIA cell, producing one daughter cell homozygous for the y mutation and doubly mutant for DI and Ser, plus another daughter cell homozygous for the marker $\mathrm{Sb}$ and wildtype for DI and Ser (Fig. 4E). Similar results were obtained using the bristle and epidermal hair morphology marker forked (f) as an independent marker for DI Ser double mutant clones (Fig. 3C). In these experiments, the presence of $\mathrm{DI}$ and Ser gene function in the surrounding epidermal cells-which displayed a genetic marker indicative of cells heterozygous for DI and Ser mutationswas not sufficient to rescue the cell fate transformation within the SOL. Thus, the elimination of DI and Ser activities from only one of the two daughter cells of IIA could cause the transformation of a socket into a shaft cell.

We further examined the cell fate choice in the division of the IIB cell. Previous experiments with $\mathrm{N}^{\text {ts }}$ indicate that loss of $\mathrm{N}$ function leads to the transformation of the sheath cells into neurons during the division of the IIB cell (Hartenstein and Posakony 1990; Parks and M uskavitch 1993; Wang et al. 1997). We used sca-Gal4 UASFLP, which appears to be more efficient in producing mitotic recombination than Gal $4^{109-68}$ UAS-FLP. N ota containing DI Ser double mutant clones gave rise predominantly to normal clusters, each composed of one neuron and one sheath cell, as well as some abnormal clusters of cells with the following three phenotypes: three neurons and one sheath cell; two neurons with no sheath cells; and two neurons with two sheath cells (Fig. $3 D$ ). If a recombination event occurred during the division of the SOP cell, the lack of DI and Ser function in one of its daughter cells could result in the appearance of two IIB cells (Fig. 4D). U pon subsequent divisions, the IIB cell with wild-type DI and Ser function would produce one neuron and one sheath cell. The other sibling IIB cell, which was homozygous for DI Ser mutations, 


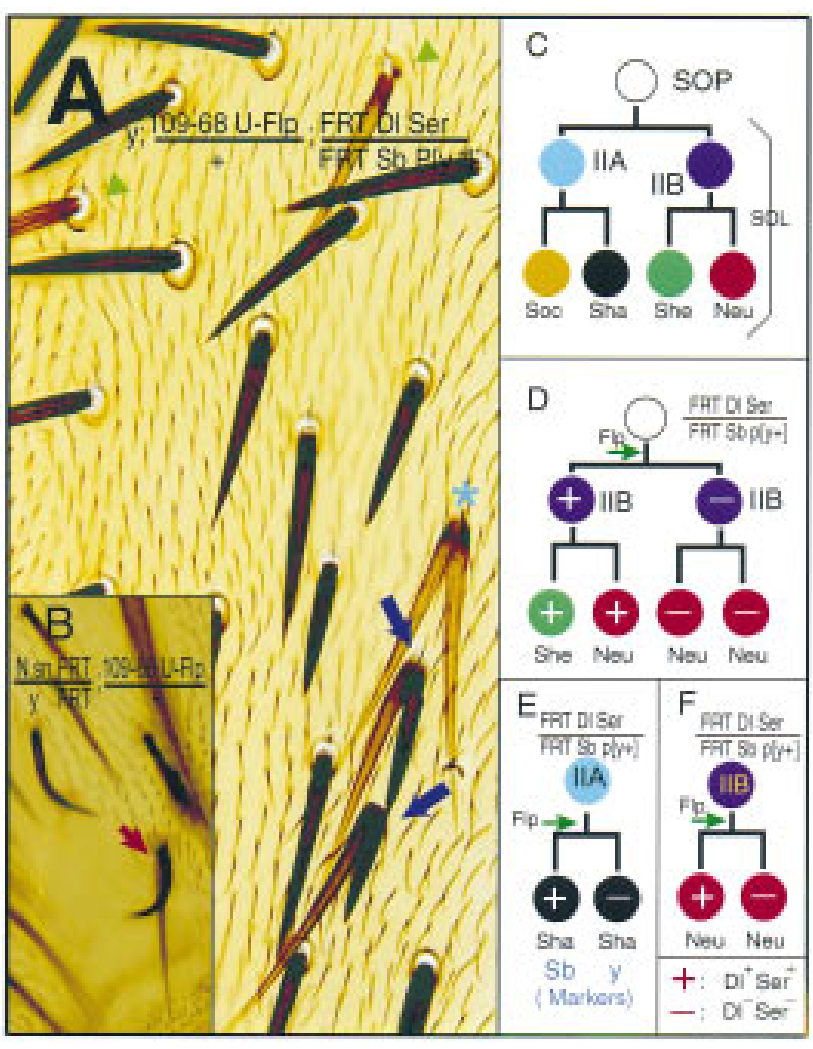

Figure 4. The sensory organ cell fate specification is mainly mediated by $\mathrm{N}$ signaling between the daughter cells of asymmetric divisions. (A) DI Ser double-mutant clones. Cell fate transformations is manifested by two distinctly marked shafts without associated sockets (purple arrows). The DI Ser mutant shaft is long $\left(\mathrm{Sb}^{+}\right)$and light $(\mathrm{y})$, whereas its sibling, the $\mathrm{DI}^{+} \mathrm{Ser}^{+}$ shaft is short $(\mathrm{Sb})$ and dark $\left(\mathrm{y}^{+}\right)$. The other two shafts, both $\mathrm{Sb}^{+}$ and y (star), could be due to an earlier loss of DI and Ser from the parental IIA cell, which then divides symmetrically to produce two shafts. Two light (y) DI Ser mutant shafts (green arrowheads) are found each associated with one socket, whose genotype cannot be determined. (B) A mutant bristle consists of one $\mathrm{N}$ mutant shaft marked with sn and $\mathrm{y}^{+}$and one shaft wild type for $\mathrm{N}$ marked with $\mathrm{sn}^{+}$and $\mathrm{y}$. (C) The fixed pattern of cell divisions in a wild-type SOL. (D) One possible outcome of mitotic recombination during the SOP division. (E) A possible mechanism for the phenotype shown in A. (F) Mitotic recombination in the division of the IIB cell could lead to the two neurons with no sheath cell phenotype, as pictured in Fig. 3D. ( + ) The cell is wild type for DI and Ser; $(-)$ the cell is homozygous mutant for DI and Ser.

could produce two neurons due to the failure in $\mathrm{N}$ signaling, thereby leading to the phenotype of three neurons and one sheath cell in a cluster (Fig. 4D). Alternatively, the IIB cell homozygous for DI Ser mutations might produce one neuron and one sheath cell due to partial transformation or to the occasional supply of the $\mathrm{N}$ ligands by other cells such as the sibling IIB cell and its progeny, which were wild type for DI and Ser. This could account for the presence of two neurons and two sheath cells in a cluster. Finally, a cluster of two neurons with no sheath cells could be generated if the mitotic recom- bination was induced later during the division of the IIB cell (Fig. 4F).

The requirement of $\mathrm{N}$ ligand function within the $\mathrm{SOL}$ demonstrates that interactions between sibling cells play an important role in specifying cell fates and rules out a situation depicted in model A (Fig. 1). However, our results do not exclude the possibility that surrounding epidermal cells might also contribute as a source of $\mathrm{N}$ ligands, in addition to the signaling between the sibling cells within the SOL. Thus, our results are compatible with either model B or C (Fig. 1). This is in contrast to the asymmetric division that gives rise to the embryonic MP2 cells of the CNS, where the N ligand is thought to be supplied exclusively from cells outside the lineage (Spana and Doe 1996).

Ser function is redundant to DI function during wing vein formation

The discovery of the redundant Ser and DI functions prompted us to ask whether Ser also plays a rol e in other DI-N signaling processes. The Gal ${ }^{109-68}$ UAS-FLP al so induces FRT recombination in longitudinal wing vein cells. M ost members of the $\mathrm{N}$ signaling pathway are al so involved in the restriction of the venation to a stripe of cells from larger vein-competent territories, a process similar to lateral inhibition during neurogenesis (Sturtevant and Bier 1995; de Celis et al. 1997; Huppert et al. 1997). Removal of DI in wing mosaics led to only modest expansions of the vein into the intervein area (Fig. 5B), whereas removal of Ser had no detectable phenotype (Fig. $5 A)$. In contrast, simul taneous loss of both Ser and DI in wing vein mosaics brought about noticeably larger and more frequent thickening of the veins (Fig. 5C). We believe that Ser is also redundant to DI in wing vein patterning.

The source and identity of the $\mathrm{N}$ ligands could be context dependent

Previous studies have shown that Ser can partially substitute for DI when expressed ectopically at high levels (Gu et al. 1995; Hukriede et al. 1997). In this study we show that these two $\mathrm{N}$ ligands serve redundant functions in specifying the fates of the SOP daughter cells, probably by acting in one daughter cell to promote the cell fate specification of the other daughter cell. We found that DI and Ser al so have redundant functions in patterning wing veins. In contrast, DI and Ser are known to serve distinct functions in specifying dorsal-ventral compartment boundary of the wing (wing margin). Ser in dorsal cells signals to $\mathrm{N}$ in ventral cells, and DI in ventral cells signals to $\mathrm{N}$ in dorsal cells (Diaz-Benjumea and Cohen 1995; Doherty et al. 1996; Jonsson and Knust 1996; de Celis et al 1997; M icchelli et al. 1997). For DI and Ser to provide distinct signals from one compartment to the other without generating signals among cells within the same compartment, it may be necessary to involve other factors such as that encoded by the dorsally expressed gene fringe (fng), which inhibits a cell's ability to respond 


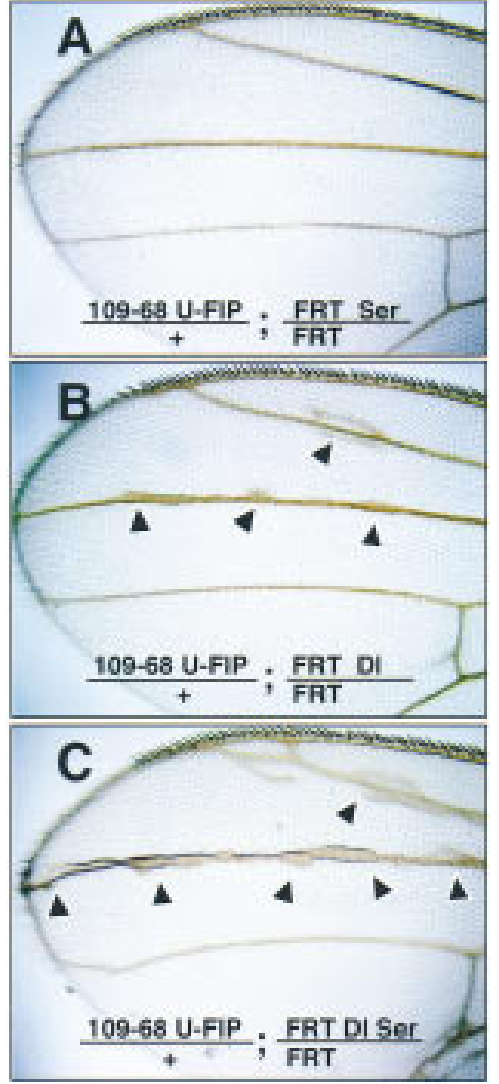

Figure 5. Ser serves a function that is redundant to $D I$ in wing vein patterning. (A) Ser mutant clones; (B) DI mutant clones; (C) $\mathrm{DI}$ and Ser double mutant clones. (Arrowheads) Vein hypertrophy.

to Ser and potentiates a cell's response to DI (Fleming et al. 1997; Panin et al. 1997).

$\mathrm{N}$ signaling is used in many processes throughout Drosophila development, such as during oogenesis, neurogenesis, muscle formation, wing patterning, and eye development (for review, see Artavanis-Tsakonas et al. 1995). N homologs also play important roles in developmental processes in organisms ranging from $\mathrm{C}$ aenorhabditis elegans, Xenopus, chick, and mouse to man, which may utilize multiple $\mathrm{N}$ ligands that are similar to DI and Ser (for review, see Lewis 1996). Whereas some of these developmental processes may employ different $\mathrm{N}$ ligands for distinct signaling events, our studies underscore the possibility of multiple $\mathrm{N}$ ligands serving redundant functions. In both sensory organ cell fate specification and wing vein patterning, the function of Ser is revealed only after $\mathrm{DI}$ is removed. Thus, multiple $\mathrm{N} \mathrm{Ii-}$ gands serving redundant function may be more prevalent than previously appreciated. It will be of interest to determine the extent to which the redundant $\mathrm{N}$ signaling using multiple ligands is exploited in various developmental contexts.

\section{Materials and methods}

Gereration of large mitotic clones

For making large clones, 24- to 48-hr AEL (after egg laying) larvae were heat shocked at $39^{\circ} \mathrm{C}$ for $1 \mathrm{hr}$. The genetic crosses were as foll ows: (1) For $\mathrm{N}$ clones, $\mathrm{W} \mathrm{N}^{55 e 11}$ sn FRT[18A]/W $\mathrm{Y} \mathrm{N} \mathrm{N}^{+}$males were crossed to $\mathrm{w}$ FRT [18A ]/FM 6; hs-FLP²/CyO females (Fig. 2A). (2) For DI clones, pr pwn/+; FRT [82B] DIRevF10 e/Ki males were crossed to pr pwn/pr pwn hs-FLP2; FRT [82B] kar ry/FRT [82B] kar ry Dp(2;3) P32[pwn+] females (Fig. 2B; Heitzler et al. 1996). DI ${ }^{9039}, \mathrm{DI}^{82-23}, \mathrm{DI}^{10 \mathrm{G} 114}$, and $\mathrm{DI}^{8 \mathrm{c} 3 \mathrm{rrev}^{1}}$ were al so tested and found to give similar mosaic phenotype as DI RevF10 (data not shown). (3) For Ser clones, y w; FRT [82B] e Ser ${ }^{R \times 82} / T M$ males were crossed to y w hs-FLP ${ }^{1}$; FRT [82B] P[y ${ }^{+}$females (Fig. 2C). Ser ${ }^{R \times 106}$ and Ser rev6-1 gave similar results (data not shown). (4) For DI Ser clones, pr pwn/ +; FRT [82B] DIRevF10 e Ser ${ }^{R \times 82 / K i}$ males were crossed to pr pwn/pr pwn hs-FLP2; FRT [82B] kar ry/ FRT [82B] kar ry Dp(2;3) P32[pwn +] (Fig. 2D; Heitzler et al. 1996). DI ${ }^{9039}$ Ser $^{R \times 106}, \mathrm{DI}^{\text {RevF10 Ser }}{ }^{\mathrm{R} \times 106}$, and DI RevF10 $\mathrm{Ser}^{r 6-1}$ were al so tested (data not shown).

We obtained the same results when the DI, Ser, or DI Ser clones are marked by the lost of $\left.\mathrm{P}^{+} \mathrm{y}^{+}, \mathrm{P}^{+} \mathrm{f}^{+}\right], \mathrm{pwn}^{+}$or by Sb (data not shown).

Generation of SOL-specific mitotic clones

For making SOL-specific clones, y w f ${ }^{36 a}$; Gal $4^{109-68}$ P[UAS-FLP, $\left.w^{+}\right]^{2}$; FRT [82B] P[f $\left.{ }^{+}\right]$females were crossed to the following males at $25^{\circ} \mathrm{C}$, and male progeny was scored for phenotype. (1) For Ser mosaics, y w; FRT [82B] Ser ${ }^{\mathrm{R} \times 82} / \mathrm{TM} 3$ (Fig. 3A). Ser ${ }^{\mathrm{R} \times 106}$ and Ser ${ }^{\text {rev6-1 }}$ gave similar results (data not shown). (2) For DI mosaics, y w; FRT [82B] DI RevF10/TM 3 (Fig. 3B). $\mathrm{DI}^{9 \mathrm{p} 39}, \mathrm{DI}^{82-23}, \mathrm{DI}^{10 \mathrm{G} 114}$, and $\mathrm{DI}{ }^{8 \mathrm{c} 3 r e v 1}$ were al so tested (data not shown). (3) For DI Ser mosaics, y w; FRT [82B] DI ${ }^{\text {RevF10 }}$ Ser $^{\mathrm{R} \times 82} / \mathrm{TM} 3$ (Fig. 3C). $\mathrm{DI}^{9 \mathrm{p} 39} \mathrm{Ser}^{\mathrm{R} \times 106}, \mathrm{DI}^{\mathrm{RevF} 10} \mathrm{Ser}^{\mathrm{R} \times 106}$, and DI RevF10 $\mathrm{Ser}^{\mathrm{r} 6-1}$ were also tested (data not shown).

For doubly marked DI Ser mosaics, y w; Gal4 ${ }^{109-68}$ P[UAS-FLP, w+]; FRT [82B] Sb ${ }^{63 b} \mathrm{P}^{+} \mathrm{y}^{+}$] females were crossed to y w; FRT [82B] DI RevF10 $\mathrm{Ser}^{\mathrm{R} \times 82} / \mathrm{TM} 3$ males (Fig. 4A).

For doubly marked $\mathrm{N}$ mosaics, $w \mathrm{~N}^{55 e 11}$ sn FRT[18A]/FM 6 females were crossed to y w FRT[18A]; Gal4 ${ }^{109-68}$ P[UAS-FLP, $\left.w^{+}\right]^{2} /$ CyO males (Fig. 4B).

For examining neuron-sheath cell fate decisions, DI Ser mosaics were produced by crossing y w; Sca-Gal4 P[UAS-FLP, $\left.w^{+}\right]^{2}$; FRT [82B] $\left.\mathrm{PLy}^{+}\right]$ females to $y$ w; FRT [82B] DIRevF10 Ser ${ }^{R \times 82} / T$ M $6 B$ males. $N$ on-Tb pupae were collected at 24-30 hr APF (after pupal formation) for dissection.

Immunostaining of the dissected pupal nota

Pupal nota were dissected in PBS and fixed for $10 \mathrm{~min}$ in $5 \%$ formal dehyde. Neuronal maker mouse mAb 9F8A9 against Elav (obtained from Devel opmental Studies Hybridoma Bank, U niversity of lowa) was used at 1:100 dilution and detected by Cy3-conjugated secondary antibodies. Sheath cell marker rabbit anti-Prospero antibody (Vaessin et al. 1991) was used at 1:1000 dilution and detected by FITC-conjugated secondary antibodies. A Z-series was obtained from MRC-600 confocal microscope and assembled in Adobe Photoshop and Adobe Illustrator (Fig. 2D).

\section{Acknowledgments}

We thank J. Duffy, D. Harrison, and N. Perrimon for allowing us to use P[UAS-FLP, $\left.w^{+}\right]^{2}$ transgenic lines before publication; T. Xu, J.A. CamposOrtega, R.J. Fleming, E. Knust, P. Simpson, P. Heitzler, M. Haenlin, S.B. Carroll, V.G. Corces, H.-M. Chung, G. Struhl, and the Bloomington Stock Center for fly strains, antibodies, and DN A sequences; and S. Abdelilah, D. Doherty, Y.M. Chan, J. Brenman, L. Ma and other members of the Jan laboratory for discussion and comments on the manuscript. C.Z. is supported by a postdoctoral fellowship from the $\mathrm{N}$ ational Institutes of Health (Public Health Service 416-5). S.Y.-S. is a research associate and L.Y.J. and Y.N .J. are investigators of the Howard Hughes Medical Institute.

The publication costs of this article were defrayed in part by payment of page charges. This article must therefore be hereby marked "advertisement" in accordance with 18 USC section 1734 solely to indicate this fact.

\section{References}

Artavanis-Tsakonas, S., K. M atsuno, and M.E. Fortini. 1995. Notch signaling. Science 268: 225-232.

Bodmer, R., R. Carretto, and Y.N. Jan. 1989. N eurogenesis of the peripheral nervous system in Drosophila embryos: DNA replication patterns and cell lineages. Neuron 3: 21-32.

Brand, A.H. and N. Perrimon. 1993. Targeted gene expression as a means 
of altering cell fates and generating dominant phenotypes. Development 118: 401-415.

de Celis, J.F., S. Bray, and A. Garcia-Bellido. 1997. Notch signalling regulates veinlet expression and establishes boundaries between veins and interveins in the Drosophila wing. Development 124: 1919-1928.

de Celis, J.F., M. Mari-Beffa, and A. Garcia-Bellido. 1991. Cell-autonomous role of $\mathrm{N}$ otch, an epidermal growth factor homologue, in sensory organ differentiation in Drosophila. Proc. Natl. Acad. Sci. 88: 632-636.

Diaz-Benjumea, F.J. and S.M . Cohen. 1995. Serrate signals through N otch to establish a Wingless-dependent organizer at the dorsal/ventral compartment boundary of the Drosophila wing. Development 121: $4215-4225$.

Doherty, D., G. Feger, S. Younger-Shepherd, L.Y. Jan, and Y.N . Jan. 1996. Delta is a ventral to dorsal signal complementary to Serrate, another Notch ligand, in Drosophila wing formation. Genes \& Dev. 10: 421434.

Fehon, R.G., P.J. Kooh, I. Rebay, C.L. Regan, T. Xu, M.A. Muskavitch, and S. Artavanis-T sakonas. 1990. M olecular interactions between the protein products of the neurogenic loci Notch and Delta, two EGFhomologous genes in Drosophila. Cell 61: 523-534.

Fleming, R.J., T.N. Scottgale, R.J. Diederich, and S. Artavanis-T sakonas. 1990. The gene Serrate encodes a putative EGF-like transmembrane protein essential for proper ectodermal development in Drosophila melanogaster. Genes \& Dev. 4: 2188-2201.

Fleming, R.J., Y. Gu, and N .A. Hukriede. 1997. Serrate-mediated activation of $\mathrm{N}$ otch is specifical ly blocked by the product of the gene fringe in the dorsal compartment of the Drosophila wing imaginal disc. Development 124: 2973-2981.

Frise, E., J.A. Knoblich, S. Younger-Shepherd, L.Y. Jan, and Y.N. Jan. 1996. The Drosophila N umb protein inhibits signaling of the $\mathrm{N}$ otch receptor during cell-cell interaction in sensory organ lineage. Proc. Natl. Acad. Sci. 93: 11925-11932.

Golic, K.G. and S. Lindquist. 1989. The FLP recombinase of yeast cataIyzes site-specific recombination in the Drosophila genome. Cell 59: 499-509.

Gu, Y., N.A. Hukriede, and R.J. Fleming. 1995. Serrate expression can functionally replace Delta activity during neuroblast segregation in the Drosophila embryo. Development 121: 855-865.

Guo, M., L.Y. Jan, and Y.N. Jan. 1996. Control of daughter cell fates during asymmetric division: interaction of $\mathrm{N}$ umb and $\mathrm{N}$ otch. Neuron 17: $27-41$.

Hartenstein, V. and J.W. Posakony. 1989. Development of adult sensilla on the wing and notum of Drosophila melanogaster. Development 107: 389-405.

- - 1990. A dual function of the $\mathrm{N}$ otch gene in Drosophila sensillum development. Dev. Biol. 142: 13-30.

Heitzler, P. and P. Simpson. 1991. The choice of cell fate in the epidermis of Drosophila. Cell 64: 1083-1092.

1993. Altered epidermal growth factor-like sequences provide evidence for a role of $\mathrm{N}$ otch as a receptor in cell fate decisions. De velopment 117: 1113-1123.

Heitzler, P., M. Bourouis, L. Ruel, C. Carteret, and P. Simpson. 1996. Genes of the Enhancer of split and achaete-scute complexes are re quired for a regulatory loop between Notch and Delta during lateral signalling in Drosophila. Development 122: 161-171.

Hukriede, N.A., Y. Gu, and R.J. Fleming. 1997. A dominant-negative form of Serrate acts as a general antagonist of $\mathrm{N}$ otch activation. De velopment 124: 3427-3437.

Huppert, S.S., T.L. Jacobsen, and M.A.T. Muskavitch. 1997. Feedback regulation is central to Delta-Notch signalling required for Drosophila wing vein morphogenesis. Development 124: 3283-3291.

Jan, Y.N. and L.Y. Jan. 1995. Maggot's hair and bug's eye: Role of cell interactions and intrinsic factors in cell fate specification. Neuron 14: 1-5.

Jonsson, F. and E. Knust. 1996. Distinct functions of the Drosophila genes Serrate and Delta revealed by ectopic expression during wing development. Dev. Genes Evol. 206: 91-101.

Lewis, J. 1996. N eurogenic genes and vertebrate neurogenesis. Curr. Opin. Neurobiol. 6: 3-10.

Micchelli, C.A., E.J. Rulifson, and S.S. Blair. 1997. The function and regulation of cut expression on the wing margin of Drosophila: $\mathrm{N}$ otch, Wingless and a dominant negative role for Delta and Serrate.
Development 124: 1485-1495.

N akao, K. and J.A. Campos-Ortega. 1996. Persistent expression of genes of the enhancer of split complex suppresses neural development in Drosophila. Neuron 16: 275-286.

Panin, V.M., V. Papayannopoulos, R. Wilson, and K.D. Irvine. 1997 Fringe modulates $\mathrm{N}$ otch-ligand interactions. Nature 387: 908-912.

Parks, A.L. and M.A. Muskavitch. 1993. Delta function is required for bristle organ determination and morphogenesis in Drosophila. Dev. Biol. 157: 484-496.

Parks, A.L., S.S. Huppert, and M .A. M uskavitch. 1997. The dynamics of neurogenic signalling underlying bristle development in Drosophila melanogaster. Mech. Dev. 63: 61-74.

Posakony, J.W. 1994. N ature versus nurture: Asymmetric cell divisions in Drosophila bristle development. Cell 76: 415-418.

Rhyu, M.S., L.Y. Jan, and Y.N. Jan. 1994. Asymmetric distribution of $\mathrm{Numb}$ protein during division of the sensory organ precursor cell confers distinct fates to daughter cells. Cell 76: 477-491.

Spana, E.P. and C.Q. Doe. 1996. N umb antagonizes $\mathrm{N}$ otch signaling to specify sibling neuron cell fates. Neuron 17: 21-26.

Speicher, S.A., U. Thomas, U. Hinz, and E. Knust. 1994. The Serrate locus of Drosophila and its role in morphogenesis of the wing imaginal discs: Control of cell proliferation. Development 120: 535-544.

Sturtevant, M.A. and E. Bier. 1995. Analysis of the genetic hierarchy guiding wing vein development in Drosophila. Development 121: 755-765.

Thomas, U., S.A. Speicher, and E. Knust. 1991. The Drosophila gene Serrate encodes an EGF-like transmembrane protein with a complex expression pattern in embryos and wing discs. Development 111: $749-761$.

Vaessin, H., E. Grell, E. Wolff, E. Bier, L.Y. Jan, and Y.N. Jan. 1991. Prospero is expressed in neuronal precursors and encodes a nuclear protein that is involved in the control of axonal outgrowth in Drosophila. Cell 67: 941-953.

Wang, S., S. Younger-Shepherd, L.Y. Jan, and Y.N . Jan. 1997. Only a subset of the binary cell fate decisions mediated by $\mathrm{N}$ umb/ $\mathrm{N}$ otch signaling in Drosophila sensory organ lineage requires Suppressor of Hairless. De velopment 124: 4435-4446.

Xu, T. and G.M. Rubin. 1993. Analysis of genetic mosaics in developing and adult Drosophila tissues. Development 117: 1223-1237. 


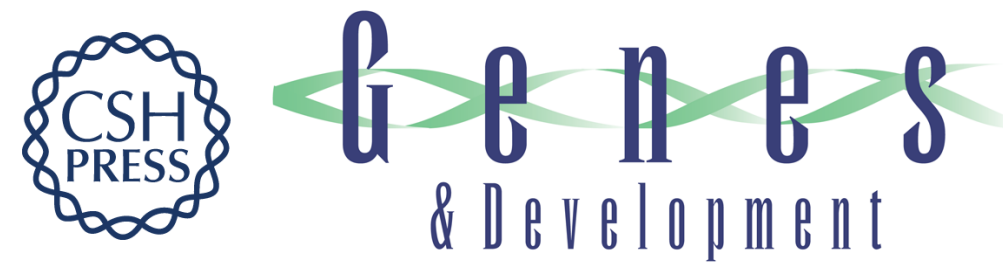

\section{Delta and Serrate are redundant Notch ligands required for asymmetric cell divisions within the Drosophila sensory organ lineage}

Chaoyang Zeng, Susan Younger-Shepherd, Lily Y. Jan, et al.

Genes Dev. 1998, 12:

References This article cites 38 articles, 21 of which can be accessed free at:

http://genesdev.cshlp.org/content/12/8/1086.full.html\#ref-list-1

License

Email Alerting Receive free email alerts when new articles cite this article - sign up in the box at the top Service right corner of the article or click here.

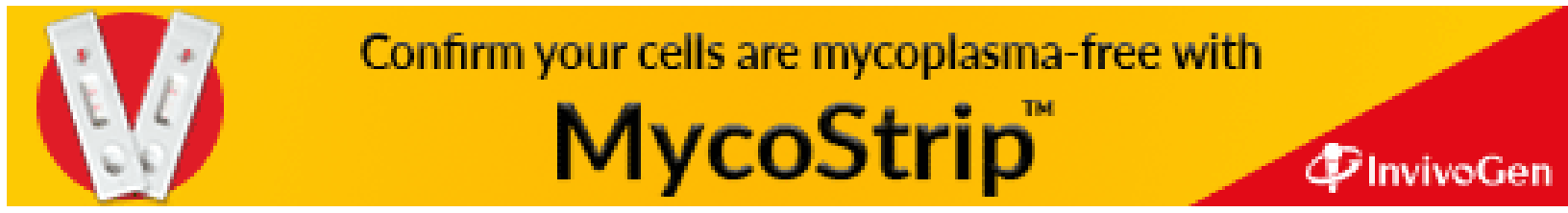

